\title{
Two distinct clinical presentations in adult unicuspid aortic valve
}

\author{
Arvind K. Agnihotri, MD, ${ }^{a}$ Shaun C. Desai, BA, ${ }^{a}$ Yong-Qiang Lai, MD, ${ }^{b}$ Michael G. Fitzsimons, MD, FCCP, ${ }^{c}$
}

Alan D. Hilgenberg, MD, and Gus J. Vlahakes, MD, ${ }^{a}$ Boston, Mass

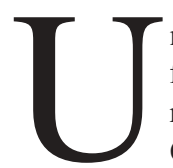

nicuspid aortic valve (UAV) is a rare congenital malformation, seen in approximately $0.02 \%$ of patients referred for echocardiography but in as many as $4 \%$ to $6 \%$ of patients undergoing operations for "pure aortic stenosis." 1,2 Of the two pathologic types, the acommisural and the unicommisural, the latter predominates in both adult and pediatric populations (Figure 1). Aortic dilatation is known to be frequent in this condition, but limited information exists.

\section{Patients}

Between January 1, 2002, and January 1, 2005, 12 patients with UAV, confirmed by both intraoperative transesophageal echocardiography and surgical inspection, underwent valve surgery at one institution (1.8\% of 671 cases). The transesophageal echocardiogram was reviewed for the following: aortic valve area, diameter of the ascending aorta, maximal and mean transaortic valve gradient, grade of aortic insufficiency, and left ventricular ejection fraction.

Eleven $(92 \%)$ of the patients were male. Age at surgery ranged from 24 to 58 years (mean: $44 \pm 9$ years [1 SD]). The presenting symptoms were angina and shortness of breath in $3(25 \%)$, angina only in 2 (17\%), and shortness of breath only in 2 (17\%). Two patients $(17 \%)$ were free of symptoms. The remaining patient had monocular blindness (emboli to the retinal artery) but had no cardiac symptoms.

\section{Operative Technique and Findings}

Valve replacement was performed with standard techniques on 11 patients. In the 12th patient, a 24 -year-old man, a flexible noncalcified valve was preserved. Mechanical valves were used in 2 patients and bovine pericardial bioprostheses in 9 patients. The ascending aorta was replaced in 7 patients. Additional procedures were performed on some patients (Table 1).

Ascending aortic dilatation $(>40 \mathrm{~mm})$ was found in 6 patients $(50 \%)$, and all underwent replacement of the ascending aorta. In the 4 patients with significant aortic insufficiency, the aorta was also replaced. Ascending aortic size was associated with younger

From the Divisions of Cardiac Surgery ${ }^{\mathrm{a}}$ and Cardiac Anesthesiology, ${ }^{\mathrm{c}}$ Massachusetts General Hospital, Harvard Medical School, Boston, Mass

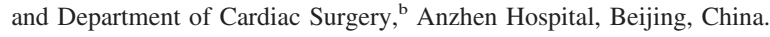

Received for publication Oct 20, 2005; accepted for publication Nov 2, 2005 .

Address for reprints: Arvind K. Agnihotri, MD, Division of Cardiac Surgery, Massachusetts General Hospital, Harvard Medical School, Edwards Research, 119, 55 Fruit St, Boston, MA 02114 (E-mail: aagnihotri@ partners.org).

J Thorac Cardiovasc Surg 2006;131:1169-70

$0022-5223 / \$ 32.00$

Copyright () 2006 by The American Association for Thoracic Surgery doi:10.1016/j.jtcvs.2005.11.040

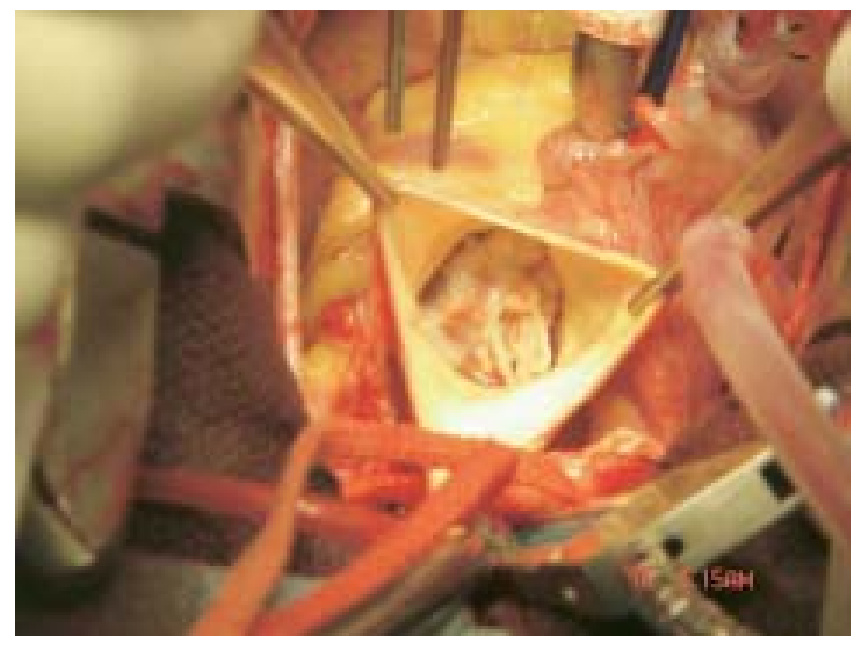

Figure 1. Severely calcified, unicommisural UAV.

age at operation $(P=.02)$. Each patient older than 47 years had an aortic size less than $40 \mathrm{~mm}$, whereas in the younger group $86 \%$ (6/7) had an aortic size greater than $45 \mathrm{~mm}$.

An "abnormal" pattern of calcification was noted in 11 patients with large volume and extension either into the proximal aorta or, in 6 patients, into the interventricular septum just lateral to its membranous component.

There were no in-hospital or late deaths. Complications included pleural or pericardial effusion in 7 patients $(58 \%)$ and third-degree heart block in 2 patients $(17 \%)$.

\section{Discussion}

We found UAVs in $1.8 \%$ of patients undergoing replacement, which is lower than figures from other reports (4\%-6\%) based on specimen examination in adult patients with isolated aortic valve stenosis. ${ }^{2}$ We included all patients having aortic valve replacement, including those who had any concomitant procedure. Differences in incidence may be due to difficulty in discriminating this condition from a severely calcified bicuspid valve. There are anatomic clues that can aid in surgical diagnosis, including the shape of the leaflet attachment zone.

The typical age presentation in this series was the fifth decade (7/12 patients). Although a few recent series have noted a similar pattern, with patients presenting in their fifth or sixth decade of life, ${ }^{3}$ the preponderance of reports suggested a much earlier presentation, in the third decade. ${ }^{1}$

This report is the first to document the relationship of pathologic dilatation of the ascending aorta and age at presentation. This separated our patients into two distinct clinical groups. 
TABLE 1. Twelve patients with UAV and their characteristics

\begin{tabular}{|c|c|c|c|c|c|c|c|}
\hline Age $(y) / \operatorname{sex}$ & AVR/replacement of aorta/other operation & AVA & AA & $\nabla \max$ & $\nabla$ mean & Al & LVEF \\
\hline $45, M$ & $\mathrm{AVR} / \mathrm{CABG}$ & 0.73 & 35 & 66 & 42 & 1 & 55 \\
\hline 24, M & Ascending + hemiarch & 1.2 & 53 & 45 & 27 & 1 & 64 \\
\hline $49, \mathrm{M}$ & AVR & $0.5^{*}$ & 33 & $110^{*}$ & - & 2 & 60 \\
\hline $47, \mathrm{M}$ & AVR/ascending/septal myomectomy & 1.1 & 50 & 103 & 63 & 4 & 74 \\
\hline $32, \mathrm{M}$ & AVR/ascending & $0.7^{*}$ & 45 & $122^{*}$ & $60^{*}$ & 2 & 58 \\
\hline $58, \mathrm{M}$ & AVR & 1.1 & 36 & 77 & 50 & 1 & 62 \\
\hline $48, \mathrm{M}$ & AVR/ascending + root & 1.2 & 37 & 60 & - & 4 & 55 \\
\hline $49, F$ & AVR/septal myomectomy & 0.7 & 30 & 81 & 46 & 1 & 75 \\
\hline $46, \mathrm{M}$ & AVR/ascending & 1.2 & 50 & 29 & 16 & 2 & 62 \\
\hline $52, \mathrm{M}$ & AVR/septal myomectomy & 1.2 & 35 & 135 & $62^{*}$ & 1 & 86 \\
\hline $42, \mathrm{M}$ & AVR/ascending & - & 50 & $77 \dagger$ & $47 \dagger$ & 3 & 60 \\
\hline $37, \mathrm{M}$ & $\mathrm{AVR} /$ ascending + hemiarch + root/CABG & 0.7 & 46 & 22 & 9 & 3 & 40 \\
\hline Avg 44.42 & & 1.01 & 40.33 & 68.67 & 41.11 & 2.08 & 62.58 \\
\hline SD 9.04 & & 0.22 & 7.58 & 34.16 & 17.44 & 1.16 & 11.66 \\
\hline
\end{tabular}

$A V R$, Aortic valve replacement; $C A B G$, coronary artery bypass graft; $A V A$, aortic valve area (mm); $A A$, Ascending aorta size (mm); $\nabla m a x$ and $\nabla m e a n$, maximal and mean transaortic valve gradient; $A l$, aortic insufficiency ( $1=$ none, $2=$ mild, $3=$ moderate, $4=$ severe); $L V E F$, left ventricular ejection fraction (\%); $A v g$, average; $S D$, standard deviation. *Most recent preoperative transesophageal echocardiogram. †Most recent postoperative transesophageal echocardiogram.

The relationship was sharp, and there was a breakpoint at age 47 (Figure 2), suggesting two different patterns of this disease. The older patients appeared to have a less aggressive form, with delayed presentation of symptoms and without aortic dilatation. In contrast, the aggressive form of unicuspid disease was associated with early symptoms and aortic involvement. The latter group may

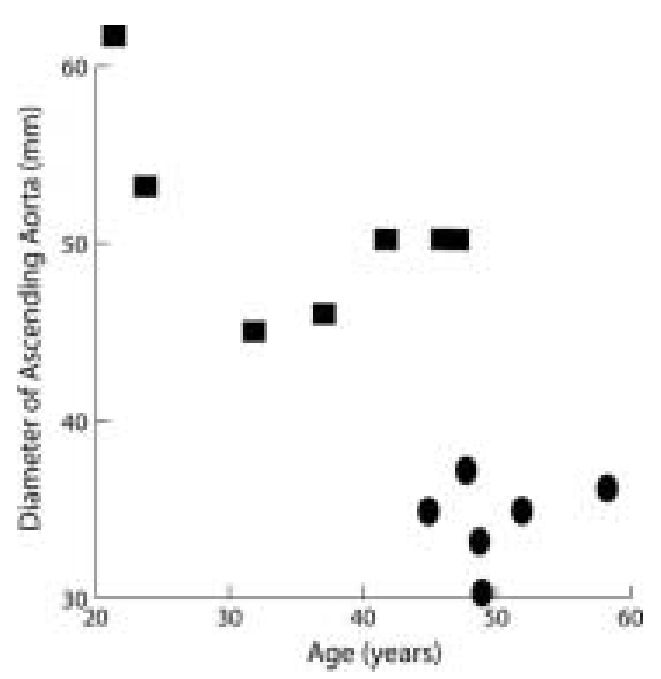

Figure 2. Aortic size at presentation versus age. This depicts a series of 12 patients undergoing replacement of UAV. The squares represent patients who had concomitant replacement of the ascending aorta; the circles represent patients in whom the ascending aorta was not replaced. There appear to be two distinct clinical presentations, earlier in life with aortic enlargement and later in life without. have similar pathologic characteristics to the much more common entity of bicuspid aortic valve and ascending aortic dilatation.

The prevalence of ascending aortic dilatation in the aggressive form of presentation leads to uniform ascending aortic replacement. This approach was taken from the experience with bicuspid disease, and our observations suggest that with older age subsequent dilatation is uncommon in the less aggressive form. ${ }^{4}$

An important observation is the abundance of calcification found in almost all patients. Particularly important for the surgeon is the $50 \%$ incidence of calcification extending into the interventricular septum, increasing the possibility of conduction system damage, which did occur in 2 of these patients. The debridement of calcium in preparation for valve implantation was undoubtedly the injuring mechanism in these patients and suggests caution in subvalvular debridement.

\section{References}

1. Novaro GM, Mishra M, Griffin BP. Incidence and echocardiographic features of congenital unicuspid aortic valve in an adult population. J Heart Valve Dis. 2003;12:674-8.

2. Roberts WC, Ko JM. Frequency by decades of unicuspid, bicuspid, and tricuspid aortic valves in adults having isolated aortic valve replacement for aortic stenosis, with or without associated aortic regurgitation. Circulation. 2005;111:920-5.

3. Stephan PJ, Henry C III, Hebeler RF Jr, Whiddon L, Roberts WC Comparison of age, gender, number of aortic valve cusps, concomitant coronary artery bypass grafting, and magnitude of left ventricularsystemic arterial peak systolic gradient in adults having aortic valve replacement for isolated aortic valve stenosis. Am J Cardiol. 1997;79: 166-72.

4. Cecconi M, Manfrin M, Moraca A, Zanoli R, Colonna PL, Bettuzzi MG, et al. Aortic dimensions in patients with bicuspid aortic valve without significant valve dysfunction. Am J Cardiol. 2005;95:292-4. 